\title{
A labour of Sisyphus? Public policy and health inequalities research in the UK from the Black and Acheson Reports to the Marmot Review
}

C. Bambra ${ }^{1}$, K.E. Smith, K². Garthwaite ${ }^{1}$, K.E. Joyce ${ }^{1}$, D.J. Hunter ${ }^{1}$.

${ }^{1}$ Wolfson Research Institute, Durham University, UK.

${ }^{2}$ Department of Social \& Policy Sciences, University of Bath, UK.

Corresponding author: Clare Bambra, Wolfson Research Institute, Durham University, Queens Campus, Stockton on Tees, TS17 6BH. clare.bambra@durham.ac.uk

Approx 4250 words

The Corresponding Author has the right to grant on behalf of all authors and does grant on behalf of all authors, an exclusive license (or non exclusive for government employees) on a worldwide basis to the BMJ Publishing Group Ltd and its Licensees to permit this article (if accepted) to be published in JECH editions and any other BMJPGL products to exploit all subsidiary rights, as set out in our license. 


\title{
A labour of Sisyphus? Public policy and health inequalities research in the UK from the Black and Acheson Reports to the Marmot Review
}

\begin{abstract}
This paper explores similarities and differences in both policy content and research context between the three main English government reports on health inequalities: the Black Report (1980), the Acheson Inquiry (1998), and the Marmot Review (2010). It finds that there are great similarities and very few differences in terms of both the theoretical principles guiding the recommendations of these reports and the focus of the recommendations themselves. However, there are clear differences in terms of the research and political contexts of each report. The Marmot review had a far larger research base upon which to build its recommendations than the previous two reports, and it was very clearly presented as an evidence-based report. The paper then speculates as to why, despite different contexts, the same recommendations were made across a 30 year period. The findings call into question the progress of health inequalities research and of the links between research, politics and policy.
\end{abstract}

153 words

Keywords: health inequalities, evidence-based policy, social determinants, research, public health. 


\section{A labour of Sisyphus? Public policy and health inequalities research in the UK from the Black and Acheson Reports to the Marmot Review}

\section{BACKGROUND}

In February 2010, the Strategic Review of Health Inequalities in England Post 2010 (Marmot Review) was published as 'Fairer Health, Fairer Lives' [1]. This latest English government commissioned report on health inequalities follows two earlier UK wide ones, the 1998 Acheson Inquiry and the 1980 Black Report (see Table 1). Like these earlier reports, the Marmot Review summarises data on the extent of health inequalities, primarily in terms of socio-economic status (though all of the reports also consider other aspects of health inequalities, such as gender, ethnic and geographic differences), and reviews the available evidence in order to make a series of recommendations for policy action. Whilst all three reports were directed to draw on the available evidence, the Marmot review had far more research on which to draw, was a larger and more inclusive consultative process (in terms of engaging policy and practice stakeholders and a wide range of academics and policy analysts via the Commissioners, three working committees and nine task groups) and was therefore expected to be more directly evidence-based, particularly in terms of evidence relating to interventions to tackle health inequalities, an area in which evidence had been lacking for both of the previous reports. In a 2009 editorial in this journal, the question was posed as to how the 'evidence-based' recommendations of the 2010 Marmot Review would differ from the 'non-evidence-based' recommendations of the 1980 Black Report [2]. In this paper, we address this question by exploring the similarities and differences between these two reports and the intervening 1998 Acheson Inquiry in terms of: (i) underpinning theoretical principles; (ii) policy recommendations; (iii) the political and research contexts in which each was released; and (iv) their actual or potential impact on research and policy. We conclude by calling into question the progress of research in health inequalities and of the links between research, politics and policy.

\section{ANALYSIS \\ (i) Underpinning theoretical principles}

One of the most noticeable differences between the three reports is that the Black Report [3] dedicated a specific amount of time to disproving arguments that evidence of health inequalities in the 
UK were the result either of artefact or of social selection. These explanations were barely mentioned in the Acheson [4] or Marmot [1] reports as, by this stage, the research that had been undertaken on health inequalities meant that these explanations were largely no longer considered realistic (e.g. $5,6,7)$. In fact, despite the very different contexts into which they were released, all three reports clearly state that health inequalities are a result of other societal inequalities and differences and all take a 'multi-causal' approach to explaining their existence. Furthermore, although the Acheson [4] and Marmot [1] reports are particularly clear in emphasising the importance of considering determinants across the whole lifecourse, and not just the point at which health inequalities are most apparent, the Black report [3] also placed a significant amount of emphasis on motherhood and the early years of life. Indeed, the Marmot Review's statement that it is the 'cumulative effects of hazards and disadvantage through life' that produce the social patterning of disease and ill health in the UK echoes almost precisely the Black Report's conclusion that 'inequalities in health tend to arise from the cumulative deprivation of a life-time'. So, in key respects, the theoretical principles underpinning each report's account of health inequalities are extremely similar.

There are, nonetheless, some key differences. For example, perhaps reflecting the desire for clear solutions, the Black report places more emphasis on 'material conditions' than either of the subsequent two reports. It is not that material determinants are always given less consideration in the Acheson or Marmot reports but, drawing on the wealth of health inequalities research undertaken since the 1980 Black Report, the complexity of the way in which material factors often interrelate with various other determinants is highlighted in the two more recent reports. This leads to a further difference - the increasing emphasis each report places on relative inequalities and psychosocial determinants (e.g. 8,9,10,11,12,13,14). The Black Report was published before psychosocial theories had emerged as a credible body of academic work and hence, unsurprisingly, does not refer to psychosocial determinants. By the time the Acheson Inquiry was being written, psychosocial theories had gained credibility within the health inequalities research community (although they continued to be contested by some until very recently, e.g. 15), particularly in relation to the work environment, on which much of the early psychosocial work focuses (e.g. 16,17). Mirroring this, the Acheson Inquiry flagged the need to 'reduce psychosocial work hazards' [4]. Perhaps unsurprisingly, given both that Michael Marmot is a leading proponent of psychosocial theories of health inequalities 
and that these theories have become increasingly widely accepted in the health inequalities research community (see 18,19,20), the Marmot Report places even more emphasis on psychosocial explanations of health inequalities, giving issues such as isolation, sense of control and individual and community empowerment far more prominence than either of the previous reports. For example, social capital, described as the 'links that bind and connect people within and between communities', is presented as a 'source of resilience' and 'a buffer against risks of poor health'. Related to this, and inspired by Amartya Sen's work (e.g. 21,22,23), the phrase 'capabilities' is used throughout the report to help illustrate the importance the review places on enabling individuals to have the opportunity to live fair and healthy lives throughout their life course.

A further, relatively subtle difference between the reports is the way in which health inequalities are framed. In the Black Report [3], although the data employed illustrate continuous improvements in health in each 'step up' in social class measures, health inequalities are nevertheless portrayed as a matter of 'health gaps'. The Acheson Inquiry [4] reflects changes in the language researchers were using by frequently referring to 'health gradients' as well as gaps. The Marmot review pushes this development further by consistently emphasising the importance of recognising that there is a 'continuing gradient of health' which affects the entire social spectrum [1]. Although the social gradient in health is not a new 'discovery', this shift in language is important because, as Graham and Kelly [24] highlight, the different ways in which the 'problem' of health inequalities is conceived of can lead to rather different conclusions about what the logical policy responses might be. This development underlies what is perhaps one of the clearest distinctions between the Marmot Review and the previous two reports, which is the introduction of the concept of 'proportionate universalism': that interventions should be both universal and targeted to where there is more need.

\section{(ii) Policy Recommendations}

Despite the existence of some theoretical differences between the three reports, as described above, many of the policy recommendations are remarkably similar. In this section, we provide a brief thematic comparison of the main recommendations. 
- Early Years and Young People: For all three reports, the recommendations relating to early years bear striking similarities. Whilst Black aimed for children to have 'a better start in life' with recommendations relating to increasing child benefits, improving pre-school childcare and providing free school meals, almost two decades later the Acheson Inquiry strongly echoed these recommendations. The Marmot Review is less directive, but as part of a policy objective to "Give every child the best start in life", various recommendations relating to maternal care, pre-school childcare and care within the education system are made.

- Education, training and employment: The Black Report and the Acheson Inquiry both focused largely on pre-school services so the Marmot Review recommendation that reducing inequalities in education outcomes should form a central part of efforts to reduce health inequalities could be said to represent a new focus. The Black Report featured no direct recommendation relating to employment either. In contrast, the Acheson Inquiry highlighted the detrimental effects of unemployment and suggested increasing opportunities for work and training. The Marmot Review continued the strong emphasis on employment and training opportunities but supplemented by an emphasis on the quality and flexibility of employment.

- Working conditions / environment: The Black reported highlighted the need for 'minimally acceptable and desirable conditions of work'. This was expanded by the Acheson Inquiry to include a call to address psychosocial work hazards. The Marmot Review further develops these concerns, placing particular emphasis on psychosocial related issues such as equality and stress. All three reports recommend that the workplace be used an arena in which to undertake health-promoting activities.

- Tackling poverty and redistributing wealth and resources: The Black Report put forward the ambitious aim of abolishing child poverty as a national goal for the 1980s, although it acknowledged that this was likely to be very costly, and also included a number of other recommendations (particularly around benefits) that were intended to tackle poverty. Fast forward to 1998 and whilst Acheson did not recommend such an ambitious goal, it too emphasised the need to tackle income inequality, specifically recommending that: 'Further 
steps should be taken to reduce income inequalities and improve living standards of poor households'. This focus is echoed in the Marmot Review, which recommends the introduction of a minimum income for healthy living and the implementation of a more progressive taxation system.

- Transport: Both Black and Acheson stressed the need to address traffic accidents. Acheson also recommended that public transport should be improved and active forms of transport, such as walking and cycling, be encouraged. The Marmot Review echoes the Acheson recommendations but this is underpinned by a new emphasis on environmental, as well as health, concerns.

- Housing: All three reports call for an upgrading of housing stock. The Black Report focused on the quality and availability of local authority housing. The Acheson Inquiry added recommendations on fuel poverty and insulation and reducing accidents in homes and placed particular emphasis on the housing of older people. The Marmot Review, less specifically, calls for the creation and development of 'healthy and sustainable places and communities' but, in the longer term, it too calls for the 'upgrade of housing stock'.

- The role of the NHS and other public services/sectors: All three reports stress the need for cross-departmental working at local and national levels of government. None of the reports suggest that the NHS can (or should) play a prominent role in addressing health inequalities but the Black Report and Acheson Inquiry both make some recommendations concerning the need to ensure fair and equal access to health care services and the Marmot Review suggests the 'prevention and early detection of those conditions most strongly related to health inequalities' should be prioritized.

- Obesity, food and physical exercise: All three reports suggest food is an important issue but they vary in the specificity of their recommendations. The Black report was relatively vague in suggesting that measures were required to 'encourage the desirable changes in people's diet [and] exercise'. In contrast, Acheson made some rather specific recommendations, including 
increasing the availability of food to ensure the supply of 'an adequate and affordable diet'. The Marmot Review is more similar to Black than Acheson, marking a return to relatively broad and unspecific suggestions such as 'efforts to reduce the social gradient in obesity.' All three reports focus on community/individual level interventions in relation to food and obesity, with none suggesting regulation of the food industry.

- Other lifestyle-behaviours: All three reports also make similar recommendations around alcohol and smoking, with all noting that people's behaviours are constrained by structural and environmental factors. Black and Acheson both recommended health education campaigns (whereas Marmot specifically notes that social marketing campaigns are often poorly designed from a health inequalities perspective). The first two reports also both made some specific recommendations concerning the supply, marketing and consumption of tobacco products, whereas Marmot does not. None of the reports make similar recommendations for alcohol.

- Climate change / sustainable development: The Marmot Review is the first of the three reports to link tackling health inequalities with environmental issues, specifying the need to 'mitigate effects of climate change' as a policy recommendation.

\section{(iii) The research and political contexts of the reports}

Having compared the policy recommendations of each report it is also necessary to consider the contexts in which each were produced and published. Focusing on the research climate first, it is clear that there are substantial differences between the three. The Black Report was published in a period in which many academics doubted even the existence of significant health inequalities within the UK as it was widely believed that the provision of a free-at-the-point-of-access health service and a broader welfare state, would tackle the health differences that had been recognised in previous eras. Hence, its publication had a huge impact on the research community, generating substantial interest in inequalities in health and contributing to an era in which a great deal of further research was undertaken, despite Conservative government disinterest in the issue (see below). 
Second, the political context of the Black and Marmot reports differed significantly from that of the Acheson Inquiry. The Black Report, which had been commissioned by a (left-wing) Labour government, reported to a Conservative government elected on a manifesto commitment to reduce public spending. It was in this context that the Black Report's policy recommendations were wholeheartedly rejected and efforts made to minimise the media and public interest in it (the report was officially published on a Bank Holiday Monday and initially only 260 copies were produced on poor-quality paper). In an infamous foreword to the report, Patrick Jenkins, the then Secretary of State for Social Services, claimed the report was 'wildly unrealistic' and 'seriously flawed' [25, p.126]. Some commentators have suggested that the authors of the Black Report were naïve not to appreciate that they might be reporting to a Conservative government and that, while it may have been a lost cause, they failed to position the report to reflect political reality. For example, Illsley [26] argues that Black's recommendations would have presented problems for any government as it contained a 130 page 'wish list' and was therefore, given the UK's economic difficulties at the time, 'a report waiting to be rejected'.

In contrast, the 1998 Acheson Inquiry was commissioned by the newly elected Labour government (by Tessa Jowell, the first public health minister) which had achieved a landslide victory and had been elected on a manifesto which highlighted the need to tackle various social inequalities and promised to tackle the 'root causes' of ill health, such as poor housing and unemployment [27]. Its recommendations were officially welcomed and the government stressed that they were already implementing many of them [28].

When the Marmot Review was commissioned more than a decade later in 2008 , it was by a Labour government that was coming towards the end of its third term and was not enjoying public or media support. The government had also by this stage moved some way from its initial commitment to tackling the 'upstream' structural determinants of health and was more focused on 'downstream' individual life-style factors - an example of Whitehead's 'lifestyle drift' thesis $[29,30]$. Further, unlike the two earlier UK wide reports, the Marmot Review was commissioned by the English Department of Health and as such did not cover Scotland, Wales or Northern Ireland as health is a devolved 
responsibility. Within three months of being published, a Conservative-Liberal Democrat coalition formed a new government. Indeed, as Hunter et al. [31] have commented, the timing of the Marmot Review has 'eerie echoes' of the Black report in the sense that it was commissioned under a Labour government but the decision to implement (or not) many of its recommendations has fallen to a Conservative-led government. Awareness of this political context may have influenced how the Marmot Review was drafted, possibly informing the decision to make rather vague and diluted recommendations (see below) which could be interpreted by, and remain acceptable to, different ideological perspectives and thus avoid the political marginalisation which befell the Black Report in the 1980s. In addition, the international banking crisis and high levels of debt facing the UK mean this is once again a period in which the government is committed to reducing public expenditure.

\section{(iv) Research and policy impacts}

It is perhaps understandable that the 1998 Acheson Inquiry recommendations were remarkably similar to those of the 1980 Black Report, given that health inequalities had been ignored by the Conservative government in the period between the two [32]. Indeed, it is widely accepted that, as a result of the changed political circumstances of the 1980s, the immediate political impact of the Black Report was minimal. It is more worrying that the Marmot Review's recommendations continue to emphasise so many of the same issues as the two previous reports as this suggests, as others have claimed $[33,34,35,36]$, that the impact of research into health inequalities, much of which was collated in the Acheson Inquiry, has actually had very little impact on policy. After all, the same recommendations would not need to be made if they had already been, or were being, implemented effectively. This situation occurred despite the fact that the Labour government which commissioned and received the Acheson Inquiry was not only committed to reducing health inequalities $[28,37,38,39,40,41]$ but was also promoting an ethos of 'evidence-based policy' [42,43]. A radical shift in thinking and in actions is needed in order to ensure that, in 2020 and beyond, the exact same criticisms are not being levelled at official responses to the Marmot Review's recommendations. Unfortunately, however, the current political and economic context does not suggest such a shift is likely. Indeed, given that the Marmot Review has been published in a far less hospitable economic climate than its predecessor, the public health community in the UK would probably be unwise to invest too much hope in the policy impact of this review, at least in the short-term. 
A further cause for concern may be the relatively vague nature of many of the final policy recommendations in the Marmot Review. This ambiguity contrasts with the specific recommendations put forward by the various task groups (see for example those put forward by Task Group 8 on Priority Public Health Conditions) [44,45]. Whilst this vagueness may allow decision-makers of different political persuasions and working in different contexts to appropriately adapt and interpret the recommendations, it may also facilitate a situation in which positive rhetorical comments about the Review's recommendations are made but which remain unsupported by any substantial policy actions.. In addition to the dangers posed by ambiguity, the emphasis which the Marmot Review places on psychosocial issues may also back-fire. For, as Smith $[35,36]$ illustrates, there has been a tendency within UK policy circles to focus on the non-material incarnations of inequality that psychosocial theories emphasise, such as feelings of stress, happiness, fear, confidence and being in control, whilst ignoring the underlying, more material and structural sources of these feelings and experiences. This could lead to policies which attempt to tackle health inequalities by trying to 'empower' people or encouraging them to feel happier, more confident or more responsible, without necessarily addressing the key, underlying issues. Much like interventions such as 'nudge' economic incentives which focus on trying to change individual lifestyle-behaviours without also addressing some the broader, contextual factors that shape people's lifestyle 'choices', there is little evidence to indicate that trying to improve people's psychosocial experiences without introducing accompanying interventions to address the material and structural determinants with which they are associated will succeed $[15,46]$. Similar concerns may be warranted for the Marmot Review's 'capabilities' discourse, which could be translated into policy in ways which merely shift the responsibility for poor health onto individuals and communities who fail to develop the social networks required to ensure 'resilience' against health problems.

\section{DISCUSSION}

Overall, despite the very different contexts (particularly in terms of the available research) and contrasting styles of the three reports, many of the policy recommendations are remarkably similar; a point which has already been made in relation to the Acheson and Black reports $[47,48,49]$. This 
raises questions about: (i) the failure of the policy response to these recommendations to date; and (ii) the purpose of all the subsequent (and ongoing) research.

Many others have already highlighted the failure of policymakers to take up the various evidencebased policy recommendations that have been made in relation to health inequalities over the past three decades $[33,34,35,36]$. Even an internal review of the Department of Health in England, which has the lead responsibility for health inequalities, criticised the limited use of research [50]. So it seems, despite rhetorical commitments to using evidence to inform policy and the commissioning of major evidence-based reports into health inequalities, decisions taken by the UK government have been dominated by factors other than research, factors most likely shaped by dominant political ideologies which are unsupportive of either the significant redistribution of wealth or too much government intervention [see $33,35,36,51,52$ ]. If political ideologies dominate policymaking decisions to the extent that these authors suggest, then the outlook for achieving 'evidence-based', or even 'evidence-informed', policy decisions to tackle health inequalities remains bleak [36,53]. Of course, in a democracy, evidence (however, robust) can only ever be one factor in reaching decisions. Evidence itself is rarely unequivocal, uncontested or value-free.

Alternatively, do the similarities of the policy recommendations across the three reports have more to do with failings in the ways in which research evidence has developed? For what has the purpose of all the subsequent (and ongoing) research into health inequalities been if the policy recommendations have ended up being largely the same? It is certainly the case that despite the Acheson Inquiry's call for more research into interventions to tackle health inequalities, this is an area in which the evidencebase for health inequalities remains weak $[1,54]$. The majority of contemporary empirical research on health inequalities is still descriptive (exploring the aetiological pathways of health inequalities) rather than prescriptive (evaluating what can or cannot be done to reduce health inequalities). Yet this criticism is not directed only at researchers, for if policymakers really want good evidence about what works in tackling health inequalities then they need to be far more committed to evaluating (or allowing researchers to adequately evaluate) the interventions they do implement [55]. This requires new and different ways of working between practitioners, policy makers and researchers in the generation, and production, including the co-creation, of knowledge. 
Having said all this, it is important to acknowledge that the research that has been undertaken on health inequalities has not been entirely in vain. First, the substantial body of research we now have available has probably helped keep the issue on policy (as well as research) agendas. So the basic theories about health inequalities that are outlined in the Black Report are now far more widely accepted than they were in 1980 , which means a commitment to tackling health inequalities remains on the government's agenda as set out in the Queen's Speech [56]. In this way, we could say that the research does seem to have had an influence on policy but in the kind of diffuse, 'enlightenment model' sense that Carol Weiss $[57,58]$ famously describes, rather than in any direct or instrumental sense. Second, there have been some important developments in our understandings of health inequalities and, even if these developments do not substantially realise the policy recommendations that the three reports make, they are not irrelevant either. For example, the increasing knowledge about the role psychosocial determinants play in translating material and social inequalities into health inequalities has alerted our attention to the need to ensure that policies which aim to tackle material and economic inequalities do so in a way which is sensitive to social and psychological issues. So we are more aware, for example, of the need to think about social networks when considering housing interventions, and the need to consider issues of disempowerment when tackling poverty, and to think about quality of work when addressing employment (or non-employment) issues.

\section{CONCLUSION}

In some ways, it could be argued that the research into health inequalities in the UK over the last 30 years has indeed been something of a 'Labour of Sisyphus', with the industrial scale of production of evidence resulting in little direct impact on policy and only limited progress in moving our understanding of health inequalities beyond what was known by the authors of the Black Report. However, it would perhaps be overly harsh to condemn our research endeavours on this basis. Research is in many ways the ultimate long-term game $[57,58]$ and it will therefore take time (as well as favourable political and economic circumstances) for our work to have the sort of impact on policy which we desire. Research on health inequalities kept the issue "alive" in the period of political isolation between the Black Report and the Acheson Inquiry. It also seems to have helped get health 
inequalities into the political mainstream in recent years and made health inequality an important policy issue, particularly at the local level. Yet, it is difficult to deny that UK policy responses to health inequalities have generally not been based on research evidence (Smith, 2007, 2008), and it is possible that the research community could have done more, both in terms of focusing on interventions and by being more assertive in articulating the policy implications of the evidence that does exist. Looking to the future, researchers may improve the likelihood of their research having a wider policy impact by focusing less on describing the problem and more on ways to solve it, working closely with those who are charged with the task of tackling health inequalities.

\section{Acknowledgements}

CB and KJ were both involved in Task Group 8 of the Marmot Review. DJH was a member of Working Committee 3 on delivery and implementation set up by the Marmot Review.

\section{Author contribution statement}

The original idea for the paper developed out of a discussion between CB and KS. KS and KG undertook the comparative analysis of the three reports, with input from KJ. CB, KS and KG drafted the article collaboratively, with evidence input from $\mathrm{KJ}$ and conceptual and policy input from DJH. All authors contributed to editing and revising the paper.

\section{Funding}

There was no funder of this research. 


\section{$\underline{\text { References }}$}

[1] Marmot, M. (2010) Strategic review of health inequalities in England post-2010. Marmot review final report. University College London.

[2] Bambra, C. (2009) Changing the world? Reflections on the interface between social science, epidemiology and public health. Journal of Epidemiology and Community Health, (commissioned editorial), 63: 867-868.

[3] Black, D. (chair) (1980) Inequalities in health. London: Penguin.

[4] Acheson, D. (Chairman) (1998) Independent inquiry into inequalities in health. London: The Stationery Office.

[5] Fox, A. J., Goldblatt, P.O., et al. (1985). Social class mortality differentials: artefact, selection or life circumstances? Journal of Epidemiology and Community Health 39(1): 1-8.

[6] Goldblatt, P.O. (1990). Longitudinal Study: Mortality and Social Organisation. London: HMSO.

[7] Power, C., Matthews, S. et al. (1997). Inequalities in self-rated health in the 1958 birth cohort: lifetime social circumstances or social mobility? BMJ 313: 449-453.

[8] Wilkinson, R. (1997). What health tells us about society. Soundings (Special Issue: The Next Ten Years): $125-42$.

[9] Wilkinson, R. and Marmot, M. (1998). Social Determinants of Health: The Solid Facts. Copenhagen: World Health Organization.

[10] Kawachi, I., Kennedy, B.P., et al., (Eds.) (1999). Income Inequality and Health: A Reader. New York: The New Press.

[11] Marmot, M. (2004). The Status Syndrome: How Social Standing Affects Our Health and Longevity. New York: Times Books.

[12] Marmot, M. (2005). Social determinants of health inequalities. The Lancet 365(9464): 1099.

[13] Wilkinson, R. (2005). The Impact of Inequality - How to make sick societies healthier. New York, USA: The New Press.

[14] Wilkinson, R. and Pickett, K. (2009) The Spirit Level: Why More Equal Societies Almost Always Do Better. London: Penguin Books.

[15] Macleod, J. and Davey Smith, G. (2003). Psychosocial factors and public health: a suitable case for treatment? Journal of Epidemiology and Community Health 57(8): 565-70.

[16] Marmot, M., Shipley, M.J. et al. (1984). Inequalities in Death - Specific explanations of a general pattern. Lancet i: 1003-1006.

[17] Marmot, M., Bosma, H. et al. (1997). Contribution of Job Control and Other Risk Factors to Social Variations in Coronary Heart Disease Incidence. Lancet 350(9073): 235-239.

[18] Bartley, M., Sacker, A. et al. (2000). Dimensions of inequality and the health of women. In Graham, H. Understanding Inequalities in Health Buckingham, Open University Press.

[19] Elstad, J.I. (1998). The psycho-social perspective on social inequalities in health. In Pantazis, C. and Gordon, D. (Eds.) Tackling Inequalities: Where are we now and what can be done? Bristol: The Policy Press: 39-58.

[20] Dorling, D., Mitchell, R. et al. (2007). The global impact of income inequality on health by age: an observational study. BMJ 335(873): 1-5. 
[21] Sen, A. (1985). Commodities and Capabilities. Oxford: Oxford University Press.

[22] Sen, A. (1999). Development As Freedom. New York: Knopf.

[23] Sen, A. (2009) The Idea of Justice. London: Allen Lane

[24] Graham, H. and Kelly, M.P. (2004). Health inequalities: concepts, frameworks and policy. London: HDA.

[25] Jenkin, P. (2002) Dispelling the Myths of the Black Report: A Memoir. Contemporary British History, 16:3, 123-130.

[26] Illsley R (1996) 'Use of research by policy-makers: the case of research on inequalities in health' In: Barnard, K (ed) Dialogue on Research and Policy Interlinks in Public Health, WHO and Centre for Public Health Research, Sweden, Copenhagen: 1996.

[27] Labour Party (1997) New Labour because Britain deserves better (Election Manifesto). London: Labour Party.

[28] Department of Health (1998) Our healthier nation - a contract for health green paper. London: The Stationery Office.

[29] Hunter, DJ (2005) Choosing or losing health? Journal of Epidemiology and Community Health, 59: $1010-3$.

[30] Hunter DJ, Popay J, Tannahill C, Whitehead M, Elson T. (2009) Marmot review working committee 3-cross-cutting sub-group report. Learning lessons from the past: shaping a different future. www.ucl.ac.uk/gheg/marmotreview/Documents/WC3/CrossCutting.

[31] Hunter, DJ., Popay, J., Tannahill, C., and Whitehead, M. (2010) Getting to grips with health inequalities at last? BMJ, 340:c684.

[32] Bartley, M., Blane, D., \& Davey Smith, G. (1998). Introduction: beyond the Black Report. Bartley, M., Blane, D., \& Davey Smith, G. (eds.) The Sociology of Health Inequalities: 1-16.

[33] Carlisle, S. (2001). Inequalities in health: contested explanations, shifting discourses and ambiguous policies. Critical Public Health, 11(3): 267 - 281.

[34] Shaw, M., Davey Smith, G. et al. (2005). Health Inequalities and New Labour: How the promises compare with real progress. BMJ 330(7498): 1016-1021.

[35] Smith, K.E. (2007) Health inequalities in Scotland and England: the contrasting journeys of ideas from research into policy. Social Science and Medicine, 64, 1438-1449.

[36] Smith, K.E. (2008) Health inequalities in Scotland and England: the translation of ideas between research and policy. Unpublished PhD thesis, University of Edinburgh.

[37] Department of Health. (1997). Press Release: Public Health Strategy Launched to Tackle the Root Causes of III-health. London: Department of Health.

[38] Department of Health [DOH], (1999) Reducing health inequalities an action report. London: The Stationery Office.

[39] Department of Health (2001). From Vision to Reality. London, Department of Health.

[40] Department of Health (2002). Tackling health inequalities - 2002 cross-cutting review. London: Department of Health.

[41] Department of Health (2003). Tackling Health Inequalities: A Programme for Action. London, Department of Health. 
[42] Cabinet Office (1999a). Modernising Government (White Paper). London: The Stationary Office.

[43] Cabinet Office (1999b). Professional policy making for the twenty-first century. London: Cabinet Office.

[44] Bambra, C., Joyce, K., Maryon-Davies, A. (2009). Priority health conditions - Task Group 8 Report to the Strategic Review of Health Inequalities in England post-2010 (Marmot Review). http://www.ucl.ac.uk/gheg/marmotreview/Documents

[45] Bambra, C., Joyce, K.E., Bellis, M.A., Greatley, A., Greengross, S., Hughes, S., Lincoln, P., Lobstein, T., Naylor, C., Salay, R., Wiseman, M., Maryon-Davis, A., (2010). Reducing health inequalities in priority public health conditions: using rapid review to develop proposals for evidencebased policy, Journal of Public Health Advance Access published online on April 29, 2010.

[46] Adamson, J.A., Ebrahim, S. and Hunt, K. (2006) The psychosocial versus material hypothesis to explain observed inequality in disability among older adults: data from the West of Scotland Twenty07 Study. Journal of Epidemiology and Community Health 60: 974-980.

[47] Exworthy, M. (2003) The Second Black Report? The Acheson Inquiry as Another Opportunity to Tackle Health Inequalities. In Poor Health, edited by V. Berridge and S. Blume, pp. 175-97. London: Frank Cass.

[48] Marmot, M. (2001) From Black to Acheson: two decades of concern with health inequalities. A celebration of the $90^{\text {th }}$ birthday of Professor Jerry Morris. International Journal of Epidemiology, 30, 1165-1171.

[49] Birch, S. (1999) The 39 Steps: the mystery of health inequalities in the UK. Health Economics, 8, $301-308$.

[50] Capability Reviews Team. (2007). Capability Review of the Department of Health. London: Cabinet Office.

[51] Bambra, C., Fox, D., \& Scott-Samuel, A. (2005b). Towards a Politics of Health. Health Promotion International, 20(2): 187-193.

[52] Scott-Samuel, A. (2004). New Labour's new idea - Health promotion. Liverpool: Politics of Health Group.

[53] Wright, J.S.F., Parry, J. and Mathers, J. (2007). What to do about political context? Evidence synthesis, the New Deal for Communities and the possibilities for evidence-based policy. Evidence \& Policy, 3(2): 253-269.

[54] Wanless, D. (2004). Securing Good Health for the Whole Population [final report]. Norwich: HMSO.

[55] Craig, P., Dieppe, P., Macintyre, S., Michie, S., Nazareth, I. and Petticrew, M. (2008) Developing and evaluating complex interventions: the new Medical Research Council guidance. BMJ 337: 97983.

[56] HM The Queen (2010) Queen's Speech 2010. London: Houses of Parliament. Available online at: http://www.number10.gov.uk/news/speeches-and-transcripts/2010/05/queens-speech-2010-2-50580 .

[57] Weiss, C. (1977). Research for Policy's Sake: The Enlightenment Function of Social Research. Policy Analysis, 3: 531-547.

[58] Weiss, C. (1979). The Many Meanings of Research Utilization. Public Administration Review, 39(5): 426-431. 